\title{
Marital Adjustment: The Role of Perfectionism, the Ways of Coping With Stress and Gender
}

Elit Bilge Biyikoglu ${ }^{\text {* }}$, Evo Psychology \& Psychotherapy Centre, İstanbul, 34371, Turkey

Ilke Sine Egeci ${ }^{b}$, Bahcesehir University, İstanbul, 34349, Turkey

\section{Suggested Citation:}

Biyikoglu, E.B. \& Egeci, I.S. (2017). Marital Adjustment: The Role of Perfectionism, the Ways of Coping with Stress and Gender. New Trends and Issues Proceedings on Humanities and Social Sciences. [Online]. 07, pp 125138. Available from: www.prosoc.eu

Selection and peer review under responsibility of Prof. Dr. Marilyn Campbell, Queensland University of Technology, Australia

${ }^{\circledR} 2017$ SciencePark Research, Organization \& Counseling. All rights reserved.

\begin{abstract}
This study aimed to examine the concept of marital adjustment and its relation with perfectionism (self-oriented, otheroriented and socially-prescribed perfectionism), the ways of coping (problem-focused coping, emotion-focused coping and seeking social support) and gender variables. The research was carried out with 290 married individuals (188 females and 102 males). Participants were administered a questionnaire to ascertain their socio-demographic characteristics along with several assessment scales including Dyadic Adjustment Scale, Multidimensional Perfectionism Scale, The Ways of Coping Inventory, Brief Symptom Inventory. A series of analyses of Covariance (ANCOVA) was conducted to evaluate the effects of personal level of perfectionism (self-oriented, other-oriented and socially-prescribed perfectionism), the ways of coping (problem-oriented coping, emotion-oriented coping and seeking social support) and gender on marital adjustment, after controlling for psychopathological symptom levels. The results demonstrated that individuals who had self-oriented perfectionism and individuals, those who applied problem-oriented coping strategies more often, reported greater level of marital adjustment. Specifically, socially-prescribed perfectionism in males and self-oriented perfectionism in females were found to be the determinant figure on the issue of marital adjustment. Another finding revealed an interaction effect between self-oriented perfectionism and seeking social support. The findings were discussed in the light of relevant literature regarding the structure of Turkish society.
\end{abstract}

Keywords: Marital adjustment; perfectionism; coping with stress; gender;

* ADDRESS FOR CORRESPONDENCE: Elit Bilge Biyikoglu, Evo Psychology \& Psychotherapy Centre, İstanbul, 34371, Turkey

E-mail address: elitbilge@gmail.com / Tel.: +90-505-4049885 
Biyikoglu, E.B. \& Egeci , I.S. (2017). Marital Adjustment: The Role of Perfectionism, the Ways of Coping With Stress and Gender. New Trends and Issues Proceedings on Humanities and Social Sciences. [Online]. 07, pp 125-138. Available from: www.prosoc.eu

\section{Introduction}

The concept of perfectionism has been found to be related to variety of interpersonal behaviours which may affect the relationship adjustment of the couples (Hewitt, Flett \& Mikail, 1995; Haring, Hewitt, \& Flett, 2003; Stoeber, 2012). Recent conceptualization of perfectionism has been advanced by research showing that perfectionism is a multidimentional construct that includes both intrapersonal and interpersonal components. Hewitt and Flett (1991b) stated three different dimensions of perfectionism. These are self-oriented perfectionism (SOP), other-oriented perfectionism (OOP) and socially prescribed perfectionism (SPP).

SOP is defined as the generation of unrealistic high standards for and making overcritical evaluation of the self. In the literature, it is stated that SOP may adversely affect the interpersonal relations (Hill, Zrull, \& Turlington, 1997) and marital adjustment (Dimitrovsky, Levy-Shiff \& Schattner-Zanany, 2002). On the other hand, SOP found to be associated with some adaptive characteristics such as personal success, personal development and self-realization (Hewitt \& Flett, 1991 ; 1991 ; Hill et al., 1997) and adaptive coping strategies (Dunkley \& Blankstein, 2000; Flett, Russo, \& Hewitt, 1994), is also linked to stronger relationship beliefs (Flett et al., 2001, 02) and higher marriage adjustment (Habke et al., 1997). OOP and SPP are considered as interpersonal dimensions of perfectionism, and have been found to be linked with many relationship problems and poor marital relationships. OOP is defined as to set unrealistic expectations to others and to criticize the performances of others according to those expectations. The literature shows that the actor effect of the OOP is not significantly related to marital adjustment (Habke et al., 1997; Habke, Hewitt, \& Flett, 1999; Haring et al., 2003; Dimitrovsky et al., 2002); however, the partner effect might show significant findings on individuals depending on the stress factor (Hewitt and et al. 1995; Haring et al., 2003). SPP is defined as the belief that others hold unrealistic expectations for the self. Individuals high on this dimension perceive that others expect perfection from them and evaluate their performance and set unrealistic standards that the individual cannot meet. Since SPP individuals are very busy with reaching the standards of others, these individuals exhibit behavioural patterns like the fear of being negatively evaluated and avoidance of rejection and those behaviours are associated with interpersonal relationship problems in people having these characteristics (Hewitt \& Flett, 1991; Hewitt et al., 1995; Hill et al., 1997). Similarly, several studies associate SPP levels with some relationship patterns such as being socially distance, being obsessively busy with the partner, emotional addiction to the partner, lower marriage adjustment/satisfaction and lower sexual satisfaction (Hewitt \& Flett, 1991b; Hewitt et al., 1995; Hill et al., 1997; Habke et al., 1999; Flett et al., 2001-02; Dimitrovsky et al., 2002; Stoeber, 2012).

Hewitt and Flett (2002) proposed a model of perfectionistic behaviour and stress. In this model, they stated that the perfectionism is related to stress perpetuation, since the perfectionist individuals attempt maladaptive coping efforts which cause them the persistence of the stressful situations and take them away from the solution of the problem. Similarly, Hewitt, Flett and Endler (1995) stated that perfectionism leads to psychological disorders when these characteristics interact with ineffective coping efforts and also contribute to maintenance of the existed psychological disorders. Therefore, stress and poor interpersonal relationship which are associated with these three dimensions of perfectionism may lead to poor marital adjustment. In addition to investigation of perfectionist dimensions, it is also important to investigate how married individuals cope with a stressful situation.

The recognition of the importance of assessing how coping strategies used by one partner relate to marital adjustment is increasing among related literature. The studies indicate that problem-focused coping (PC) strategies including decision making, problem solving activities and direct attempts to 
control the stressful situation have a positive effect on marital adjustment (Bouchard et al., 1998; Stoneman, Gavidia-Payne, \& Floyd, 2006). Similarly, in the literature, negative coping strategies such as denial, avoidance, self-blame, withdrawal and violence are associated with lower marital adjustment; whereas positive coping strategies such as positive problem solving and optimism are associated with higher marital adjustment (Ptacek \& Dodge, 1995; Spangenberg \& Theron, 1999; Bodenmann \& Shantinath, 2004).

Emotion-focused coping (EC) strategies include the activities to mitigate the negative emotions as a result of a stressful situation (Lazarus \& Folkman, 1984; Gencoz \& Bozo, 2006). The EC strategies do not try to directly change the confronted stressful situation; it, however, aims to give new meanings to the stressful situation, regulate the related emotions or terminate the emotions (Folkman \& Lazarus, 1980). In the literature, EC strategy is associated with many negative situations like negative affect, depression, panic disorder, low social support satisfaction (Endler \& Parker, 1990; Hino, Takeuchi, \& Yamanouchi, 2002; also see Coyne \& Downey, 1991), as well as lower marital adjustment (Spangenberg \& Theron, 1999). The research conducted by Haring et al. (2003) shows that the use of negative coping strategies mediates the relationship between SPP and poorer marital functioning. Overall, the information provided by the literature addresses that the ways of coping may have an important role on marital adjustment.

Numerous studies in the literature state "gender" as an important variable determining the use of coping strategies. Accordingly, it is stated that women tend to use EC strategies in stressful situation more than men, and they tend to seek social support more often (Endler \& Parker, 1990; Ptacek, Smith, \& Dodge, 1994; Matud, 2004; Billings \& Moss, 1984; Felsten, 1998). Similarly, in the literature, gender differences are also found on the link between perfectionism and interpersonal characteristics. For instance, Hill et al. (1997) showed that the interpersonal characteristics which are associated with SOP are more positive on women comparing to men. The differences between men and women are assumed to be associated with that woman directs her perfectionist orientations towards common interpersonal pursuits (like intimacy, solidarity, protection with others in interpersonal relations); man, on the other hand, directs his perfectionist orientations towards agentic interpersonal pursuits (like maintaining the power, competence and assertion on others) (Habke \& Flynn, 2002).In light of the literature above, the purpose of the present study was to investigate the concept of marital adjustment and its relation with perfectionism (SOP, OOP and SPP), coping strategies (PC, EC and seeking social support) and gender variables, after controlling psychological symptoms of the married individuals since psychological symptoms had been shown to have an effect on marital adjustment (e.g. Overbeek, 2006; Whisman, 1999; 2007; Zaider, Heimberg, \& Lida, 2010) and perfectionist behaviours (e.g. Hewitt \& Flett, 1991a; 1991b; Blatt, 1995; for a review see Shafran \& Mansell, 2001) in the literature.

\section{Method}

\subsection{Participants}

Three hundred and five volunteered married individuals from different households who were recruited from the larger cities of Turkey participated in the study. To be eligible for the study, participants had to be married individuals and live in the same house with their partner. The final sample included 290 married individuals, 188 women (64.8\%) and 102 men (35.2\%), ranged in age from 20 to $72(M=38.97, S D=9.48)$. The mean length of the current marriage was 14.52 years $(S D=$ 
Biyikoglu, E.B. \& Egeci , I.S. (2017). Marital Adjustment: The Role of Perfectionism, the Ways of Coping With Stress and Gender. New Trends and Issues Proceedings on Humanities and Social Sciences. [Online]. 07, pp 125-138. Available from: www.prosoc.eu

9.48). The education level of the attendants was $23.1 \%(N=67)$ primary/elementary school, $28.3 \%(N$ $=82$ ) high school, and $48.6 \%(\mathrm{~N}=141)$ higher education (academy, university and graduate level).

\subsection{Instruments}

\subsubsection{Dyadic adjustment scale (DAS)}

The scale was developed by Spanier (1976) in order to assess marital quality of married and cohabitating couples. DAS is a 32-item measure comprised of four subscales measuring dyadic satisfaction, dyadic cohesion, dyadic consensus and expression of affection. The scale was adapted by Fisiloglu and Demir (2000) resulting with satisfactory psychometric properties.

\subsubsection{Multidimentional perfectionism scale (MPS)}

Perfectionism of the participants was measured using the MPS (Hewitt \& Flett, 1991b); a 45-item, 7-point Likert type instrument designed to measure the trait dimensions of SOP (unrealistic standards and perfectionistic motivations for the self), OOP (unrealistic high standards and perfectionistic motivations set for others) and SPP (the belief that others hold high standards for oneself). Higher scores on each subscale show greater perfectionism. Turkish adaptation of the MPS was conducted by Oral (1999). Similarly, Turkish version of the MPS had also satisfactory reliability and validity (Oral, 1999).

\subsubsection{The ways of coping inventory (WCI)}

WCI (Folkman \& Lazarus, 1980; 1985; Siva 1991) is a 74-item scale designed to assess a wide range of cognitive and behavioural coping strategies which individuals engage in dealing with stressful situations. The scale uses a 5-point Likert scale and has two subscales, namely; PC (engaging direct activities with the aim of reducing stress) and EC (strategies alleviating negative emotions such as distancing or avoidance). In the present study, the Turkish version of the scale was used in which three higher-order factor analyses were conducted by Gencoz et al. (2006). In this analysis, Gencoz et al. (2006) determined three factors; namely, PC, EC and indirect coping (seeking social support) and psychometric properties were established as satisfactory and valid with good internal consistency (alphas from .84 to .90).

\subsubsection{The brief symptom inventory (BSI)}

BSI (Derogatis, 1992; Sahin \& Durak, 1994) is a self-report symptom inventory developed to assess the psychological symptom status of clinical and nonclinical persons. The BSI is essentially the brief form of the Symptom Checklist 90 (SCL-90-R). The BSI is a 5-point Likert type scale and consists of 53 items and these items are selected to reflect nine symptom dimensions (somatization, obsessive compulsive disorder, depression, anxiety, phobic anxiety, paranoid thoughts, psychotism and interpersonal sensation). The global scores are interpreted as the degree of overall distress. The Turkish adaptation (Şahin \& Durak, 1994) of the inventory involves five symptom dimensions which are anxiety, depression, negative self, somatization and hostility. The BSI was used in order to control individuals' psychological symptoms. 
Biyikoglu, E.B. \& Egeci , I.S. (2017). Marital Adjustment: The Role of Perfectionism, the Ways of Coping With Stress and Gender. New Trends and Issues Proceedings on Humanities and Social Sciences. [Online]. 07, pp 125-138. Available from: www.prosoc.eu

\subsection{Procedure}

The questionnaires were administered to the participants who were recruited to the study via snowball sampling. The participants completed the questionnaires individually in approximately 20-30 minutes and returned it to the researcher in a given envelope. Prior to completing the measures, all participants completed a consent form and, following participation, all participants were debriefed.

\section{Results}

A series of analyses of Covariance (ANCOVA) was conducted to evaluate the effects of perfectionism (SOP, OOP and SPP), coping strategies (PC, EC and seeking social support) and gender on marital adjustment, after controlling for psychopathological symptom levels. Before the analysis, a median split on each independent variable was performed. Therefore, each variable categorized into two groups, yielding high and low from each perfectionism dimension and yielding often and rare use of each coping strategy. The mean scores and standard deviation values of each categorized variables were provided in Table 1.

Three separate analyses were conducted in order to calculate the differentiation between SOP, coping strategies and gender on marital adjustment, after controlling for psychopathological symptom levels: 2 (SOP: Low \& High) x 2 (PC: Rare \& Often) x 2 (Gender) ANCOVA; 2 (SOP: Low \& High) x 2 (EC: Rare \& Often) x 2 (Gender) ANCOVA; and 2 (SOP: Low \& High) x 2 (Seeking Social Support: Rare \& Often) $\times 2$ (Gender) ANCOVA. In order to control the distribution of error variance, Levene variance homogeneity was tested, before conducting these three analyses. All of these analyses showed homogeneity except the analysis of SOP, PC and gender (for PC $F[2,282]=2.22, p=0.03$; for EC $F[2$, $282]=1.30, p=.25$; and for seeking social support $F[2,282]=1.25, p=.27)$. The results of these analyses were provided in Table 2.

Table 1. The Mean Scores and Standard Deviation Values of Categorized Variables

\begin{tabular}{lcccccc}
\hline Measures & \multicolumn{2}{c}{$\mathbf{N}$} & \multicolumn{2}{c}{$\boldsymbol{M}$} & \multicolumn{2}{c}{ SD } \\
\hline Perfectionism & Low & High & Low & High & Low & High \\
Self-oriented & 154 & 136 & 62.09 & 86.54 & 10.52 & 7.17 \\
Others-oriented & 154 & 136 & 55.16 & 71.51 & 6.02 & 6.09 \\
Socially Prescribed & 145 & 145 & 48.81 & 65.11 & 6.63 & 5.57 \\
& & & & & & \\
Coping Strategies & Rare & Often & Rare & Often & Rare & Often \\
Problem-focused & 157 & 133 & 92.06 & 111.56 & 6.03 & 8.56 \\
Emotion-focused & 146 & 144 & 48.17 & 64.81 & 5.44 & 8.33 \\
Seeking social support & 157 & 133 & 33.80 & 43.60 & 4.09 & 5.02 \\
\hline
\end{tabular}

These three analyses showed that after controlling for psychopathological symptom levels, SOP (please see Table 2 for $F$ values) had a main effect on marital adjustment. Individuals who have high SOP (adjusted $M=110.0, S D=18.78$ ) show higher marital adjustment than the individuals with low SOP (adjusted $M=99.90, S D=19.91$ ). In addition, in these three analyses, the interaction effect between SOP and gender (for PC $F[1,281]=6.53, p<.05$; EC $F[1,281]=5.51, p<.05$ ); and for seeking social support $F[1,281]=5.04, p<.05)$ was found. In order to elaborate this finding, simple effect test was conducted (see Figure 1). Accordingly, among the individuals with lower levels of SOP, men (adjusted $M=104.47, \mathrm{SD}=16.82$ ) rated their marital adjustment higher than women (adjusted $M=$ 
97.35, SD = 21.09). However, for the individuals showing higher levels of SOP, men and women did not differ on marital adjustment. On the other hand, women with high SOP (adjusted $M=110.91, \mathrm{SD}=$ 17.80) have higher marital adjustment than women with low SOP (adjusted $M=97.35, S D=21.09$ ), whereas men did not show such differentiation.

Table 2. Marital Adjustment as a Function of Self-Oriented Perfectionism, Coping Strategies and Gender

\begin{tabular}{|c|c|c|c|c|}
\hline & $\begin{array}{l}\text { Sum } \\
\text { of Squares }\end{array}$ & Sd & $\begin{array}{l}\text { Mean } \\
\text { of Squares }\end{array}$ & $\boldsymbol{F}$ \\
\hline \multicolumn{5}{|c|}{ Problem-Focused Coping } \\
\hline Analysis & & & & $39.28 * * *$ \\
\hline PS & 12838.96 & 1 & 12838.96 & \\
\hline Gender & 213.33 & 1 & 213.33 & .65 \\
\hline SOP & 3313.06 & 1 & 3313.06 & $10.14^{* *}$ \\
\hline PC & 800.51 & 1 & 800.51 & 2.45 \\
\hline SOP x Gender & 2133.67 & 1 & 2133.67 & $6.53^{*}$ \\
\hline PC x Gender & .001 & 1 & .001 & .001 \\
\hline SOP x PC & 660.31 & 1 & 660.31 & 2.02 \\
\hline SOP x PC x Gender & 33.50 & 1 & 33.50 & .102 \\
\hline Error & 91845.31 & 281 & 326.85 & \\
\hline Total & 115651.25 & 289 & & \\
\hline \multicolumn{5}{|c|}{ Emotion-Focused Coping } \\
\hline \multicolumn{5}{|c|}{ Analysis } \\
\hline PS & 12252.86 & 1 & 12252.86 & $37.09 * * *$ \\
\hline Gender & 329.60 & 1 & 329.60 & .99 \\
\hline SOP & 4370.05 & 1 & 4370.05 & $13.23 * * *$ \\
\hline $\mathrm{EC}$ & 128.54 & 1 & 128.54 & .39 \\
\hline SOP x Gender & 1821.33 & 1 & 1821.33 & $5.51^{*}$ \\
\hline EC x Gender & 253.56 & 1 & 253.56 & .77 \\
\hline SOP $x \mathrm{EC}$ & 40.36 & 1 & 40.36 & .12 \\
\hline SOP x EC x Gender & 145.66 & 1 & 145.66 & .44 \\
\hline Error & 92842.16 & 281 & 330.40 & \\
\hline Total & 115651.25 & 289 & & \\
\hline \multicolumn{5}{|l|}{$\begin{array}{l}\text { Seeking Social Support } \\
\text { Analysis }\end{array}$} \\
\hline PS & 13955.79 & 1 & 13955.79 & $43.29 * * *$ \\
\hline Gender & 494.44 & 1 & 494.44 & 1.53 \\
\hline SOP & 4128.54 & 1 & 4128.54 & $12.81 * * *$ \\
\hline SSS & 140.03 & 1 & 140.03 & .43 \\
\hline SOP x Gender & 1622.97 & 1 & 1622.97 & $5.04 *$ \\
\hline SDA x Gender & 216.27 & 1 & 216.27 & .67 \\
\hline SOP $\times$ SSS & 1397.29 & 1 & 1397.29 & $4.33 *$ \\
\hline SOP $\times$ SSS $\times$ Gender & 401.24 & 1 & 401.24 & 1.25 \\
\hline Error & 90572.12 & 281 & 322.32 & \\
\hline Total & 115651.25 & 289 & & \\
\hline
\end{tabular}

PS: Psychological symptom level; SOP: Self-oriented perfectionism, PC: Problem-focused coping, EC: Emotionfocused coping, SSS: Seeking social support * $p<.05, * * p<.01, * * * p<.001$. 
Further to these findings, the interaction effect between SOP and seeking social support was also found $(F[1,281]=4.34, p<.05)$. A simple effect test was conducted to further investigate this finding (see Figure 2). When individuals did not have SOP, individuals who rarely attempted seeking social support (adjusted $M=101.87, \mathrm{SD}=17.77$ ) reported higher marital adjustment than individuals who often used this coping strategy (adjusted $M=96.71, \mathrm{SD}=22.75$ ). In contrast, among individuals who had SOP, such differentiation on marital adjustment could not be found. Additionally, when the participants who often use seeking social support had SOP (adjusted $M=111.49, \mathrm{SD}=16.46$ ) showed greater marital adjustment than participants have low SOP (adjusted $M=108.23, \mathrm{SD}=21.23$ ). However, among the individuals who often use seeking social support having SOP did not show any significant difference on marital adjustment.

\section{Figure 1. Self-Oriented Perfectionism and Gender on Marital Adjustment}

Three separate analyses were conducted in order to calculate the differentiation between SPP, coping strategies and gender on marital adjustment, after controlling psychopathological symptom levels: 2 (SPP: Low \& High) x 2 (PC: Rare \& Often) x 2 (Gender) ANCOVA; 2 (SPP: Low \& High) x 2 (EC: Rare \& Often) $\times 2$ (Gender) ANCOVA; and 2 (SPP: Low \& High) $\times 2$ (Seeking social support: Rare \& Often) $\times 2$ (Gender) ANCOVA. Levene variance homogeneity test were conducted before these analyses and variances were found to be homogenous (for PC $F[2,282]=.72, p=0.63$; for EC $F[2$, $282]=0.89, p=.51$; and for seeking social support $F[2,282]=.85, p=.55)$. The results of these analyses were provided in Table 3.

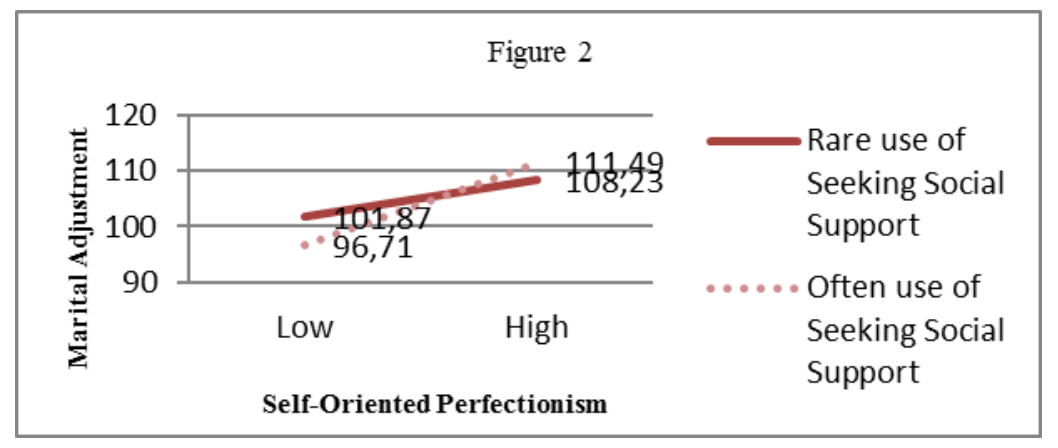

Figure 2. Self-Oriented Perfectionism and Seeking Social Support on Marital Adjustment

The analysis which involved PC showed that after controlling for psychopathological symptom levels $(F[1,281]=37.40, p<.001)$, PC had a main effect on marital adjustment $(F[1,281]=4.72, p<.01)$; referring that individuals who often used $P C$ (adjusted $M=107.40, S D=20.25$ ) reported greater marital adjustment than individuals who rarely used this coping strategy (adjusted $M=102.29, \mathrm{SD}=$ 
19.55). The same analysis also showed the interaction effect between SPP and gender $(F[1,281]=$ $4.03, p<.05$ ). The simple effect test was conducted in order to investigate the finding further (see Figure 3). Women without SPP (adjusted $M=102.91$, SD $=21.34$ ) showed lower marital adjustment than men without such perfection (adjusted $M=109.89, \mathrm{SD}=15.85$ ). In contrast, women and men with SPP did not show any significant difference on marital adjustment. Similarly, both men and women's level of marital adjustment did not differ according to the level of SPP.

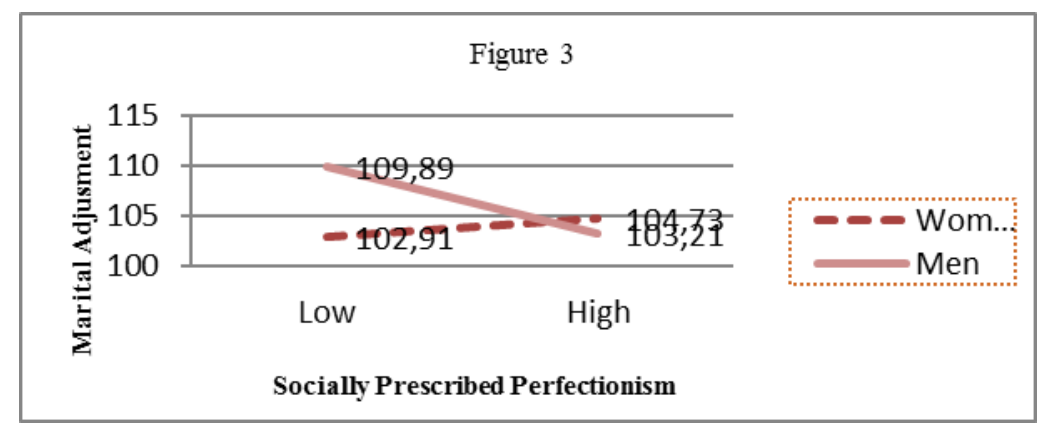

Figure 3. Socially Prescribed Perfectionism and Gender on Marital Adjustment

ANCOVA analyses which involved EC and seeking social support did not show any significant results according to the level of SPP or gender on marital adjustment, after controlling psychopathological symptom levels.

Three separate analyses were conducted in order to calculate the differentiation between OOP, coping strategies and gender on marital adjustment, after controlling psychopathological symptom levels: 2 (OOP: Low \& High) x 2 (PC: Rare \& Often) x 2 (Gender) ANCOVA; 2 (OOP: Low \& High) x 2 (EC: Rare \& Often) $\times 2$ (Gender) ANCOVA; and 2 (OOP: Low \& High) x 2 (Seeking social support: Rare \& Often) $\times 2$ (Gender) ANCOVA. In order to control the distribution of error variance, Levene variance homogeneity was tested, before conducting these three analyses and all variances were found to be homogenous (for PC $F[2,282]=1.30, p=.25$; for EC $F[2,282]=1.96, p=.06$; and for seeking social support $F[2,282]=1.24, p=.285)$. These three analyses did not show any significant findings on marital adjustment.

\section{Discussion}

The purpose of the present study was to evaluate marital adjustment by comparing individuals' level of perfectionism dimensions, coping strategies and gender in a Turkish sample. In order to meet this purpose, psychological symptoms of the participants were controlled in the study, since this variable had been shown to have an effect on marital adjustment (e.g. Overbeek, 2006; Whisman, 1999; 2007; Zaider, Heimberg, \& lida, 2010) and perfectionist behaviours (e.g. Hewitt \& Flett, 1991a; 1991b; Blatt, 1995; for a review see Shafran \& Mansell, 2001) in the literature.

In the study, it was found that the individuals who scored higher on SOP reported higher marital adjustment than those with lower levels of SOP. As stated in the literature review above, SOP does not only include setting higher standards for the self but also involve apparent motivational components. These components reserve needs for and obsessive desire of achieving the perfection, personal success and development to achieve the perfect (Hewitt \& Flett, 1991a; 1991b; Hill et al., 1997). In a of Flett et al. (2001-02) found that individuals who have higher SOP have stronger relationship study 
beliefs in the areas of communication, trust, and support, suggesting that these perfectionists have high relationship standards in these particular areas. Therefore, the individuals having SOP set goals not only for the matters related with success but also they set goals related to their intimate relationship. Literature consists of research findings supporting this argument (e.g. Flett, Sawatzky, \& Hewitt, 1995; Hill et al., 1997). Therefore, the result emerging from the present study complies with the results of the previous studies.

The findings of the present study found that there was not any significant difference between marital adjustment and OOP levels. This finding is parallel to the studies in the literature investigating the actor effect of perfectionism on marital adjustment (Habke et al., 1997; 1999; Haring et al., 2003; Dimitrovsky et al., 2002). Similarly, the current study failed to show a significant difference on marital adjustment according to the SPP levels. However, this finding draws the attention since it contradicts widely with the literature. One of the reasons why there is not any significant difference between SPP and marital adjustment in the present study may be due to higher education levels of the participants in the current study (university 48.6\%) and due to the marriage duration, which appears to be relatively long $(M=14.52, S D=10.09)$. In this context, the individuals SPP participated in the study may have built the demands and expectations of each other on realistic definitions instead of assumptions by the help of the long years they spent with their spouses and the nature of the education level that make a clear oral communication possible. As a result, since spouses know clearly what their partners expect, it may be hindered the possible relationship between SPP and marital adjustment.

The present study provided interesting findings on the interaction between perfectionism dimensions and gender. The highest level of marital adjustment was observed on women with SOP and the lowest level of marital adjustment was observed on women without SOP. However, no significant findings had been found between SOP and marital adjustment for men. Marital adjustment of the women who set higher standards for themselves was higher than the women who set lower standards for themselves. Moreover, while being a man or woman did not show any significant difference on marital adjustments of SPP individuals, SPP men reported higher marital adjustment comparing to women. When all these findings are considered together, it can be noted that SPP negatively contributes to men's marital adjustment. In the literature, SPP is associated with many negative features like psychosocial adaption problems (loneliness, shyness and fear of negative evaluation, etc.), lower social self-esteem, and inadequate social skills (Flett, Hewitt, \& De Rosa, 1996; Flett et al., 2001-02; 29; Hill et al., 1997; Hewit \& Flett, 1991b). In addition, SPP is associated with the lower marital adjustment in several studies (Hewitt et al., 1995; Haring et al., 2003; Stoeber, 2012). Different effects of SPP on gender could be explained with gender roles. That is, the communities having patriarchal social structure like Turkey, it is known that the decisions in the family are made by the man, and there is a limited diversion of duties between spouses and a sharp role separation (Kagitcibasi, 1982). Accordingly, men become responsible for supporting the family and preparing the future by taking the central decision-making role and it can be stated that such responsibility will may cause an extensive stress for men. Therefore, men who do not perceive that their environment set higher standards for them or when they do not internalize those expectations as a hard to reach standards may minimize their stress level so that they rate their marriage more positively.

On the other hand, according to the findings of the present study, one of the important factors that shaped marital adjustment for women appeared as the level of SOP. In the literature, SOP is associated with either negative situations like self-blame, guilt, depression, anxiety, anger or the adaptive characteristics like focusing on success and self-realization (Hewit \& Flett, 1991b). However, 
studies focused on gender differences suggested that SOP of women is associated with gregariousextroverted (i.e.. cheerful, friendly and enthusiastic) and warm-agreeable (i.e. accommodating, softhearted and kind) characteristics (Hill et al., 1997), positive interpersonal relationships such as social expressiveness and emotional sensitivity (Flett et al. 1996), and stronger relationship beliefs on their intimate relationships (Flett et al., 2001-02). These studies show that SOP is a positive characteristic on intimate relationships, especially on women; therefore, the finding of the study is parallel to the literature.

Another finding of Hill and et al. (1997) indicates that SOP of men is associated with negative interpersonal qualities. It is stated that SOP of men correlates with assured-dominant, arrogantcalculating and cold-hearted traits may cause controlling, manipulating, aggression toward, trying to change others, distrust, low empathy, suspiciousness, and related tendencies in their interpersonal relationships. The present study is also consistent with those research findings. In the present study, it was found that men who did not have SOP showed higher marital adjustment than women who did not have such perfectionism. Yet, while there was a negative relationship between SOP and marital adjustment for men, it was the opposite for women. It is clear that men without SOP rate their marriages more positively than women without SOP. However, the present study also showed that whether having SOP or not did not show any significant difference on men's marital adjustment. Although it appears as a contradictory finding, taking into consideration of the patriarchal Turkish societal structure -as it was mentioned above, gives additional responsibilities and duties to men- and the stress level sourced from others' expectations; SPP for men appears to be more powerful mechanism on marital adjustment as compared to SOP.

The present study also investigated the interaction between marital adjustment and the ways of coping strategies. It was found that individuals who attempted PC strategies more often reported higher marital adjustment comparing to individuals who attempted PC strategies less often. PC which involves direct attempts to control the stressful situation is associated with many positive outcomes such as higher psychological well-being, lower psychological symptoms and better health reports in the psychology literature (e.g. Endler \& Parker, 1990; Hino et al., 2002; Karademas \& Kalantzi-Azizi, 2004; Pinquart \& Silbereisen, 2008). It is also found to be linked with higher marital adjustment (Bouchard et al., 1998; Stoneman et al., 2006). Therefore, the finding of the present study is quite consistent with the literature.

In the literature, it is stated that when the confronted stressor is controllable, PC strategies are more effective, whereas when the confronted stressor is not controllable, the EC strategies are more effective (Folkman, 1984). For instance, in a study, PC strategies have been shown to fail coping with the pain of the chronic pain patients (Newth \& DeLongis, 2004). In a recent study (Marin et al., 2007), it is found that the effectiveness of EC is influenced by the perceptions of spouse responses to coping. In contrast, the relationship between PC and distress was not influenced by such responses because it involves strategies which generate solutions to a problem, or attempt to put a plan into action. In the present study, a significant difference could not be found between EC and marital adjustment. Firstly, it is believed that the perceptions of spouse responses to coping might had an influence on the results of the study as a confounding variable. On the other hand, since the PC strategies were not influenced by such perceptions, consistent results with the literature had been reached. In the future studies, it is believed to be important to control this perception. Secondly, although EC strategies are associated with negative outcomes, it should be taken into consideration that the effectiveness of coping strategies depend on the type of stress confronted and in fact both coping strategies are used a complementary in most of the stressful situations (Folkman, 1984; Lazarus, 2006). The result of the 
study might also be influenced by the individuals' type of stressors confronted while participating to the study. Therefore, it may be beneficial to control the type of current stressors confronted for the future studies.

One other noteworthy finding of the current study was that individuals who tended to seek social support and had SOP showed greater marital adjustment than the individuals who did not have SOP. The individuals with SOP have a skilful tendency towards stressful situations; they make themselves occupied with the problem until they solve it (Flett et al., 1994). Seeking social support is a step including searching for motivation from the social environment and gathering information about the problem before an active attempt to solve the problem (Gencoz et al., 2006). Taken together, it can be assumed that such approach eases marital adjustment. Similarly, individuals who tend to keep their personal standards higher, use active coping strategies (instead of coping strategies like avoidance, denial) more often, that reduces the duration of the confronted stressors (Dunkley \& Blankstein, 2000). Therefore, using such strategy, which permits acquiring information from environment as a preliminary preparation, might make marital adjustment more achievable. However, whether using seeking social support or not did not show any significant difference on marital adjustments of selforiented perfectionists. Although, this finding appeared as contradictory, self-oriented perfectionists who tend to use more active coping strategies and have more persistent tendencies to cope with the stressful situation (as stated above) could be considered to solve their problems without seeking social support despite of the benefits of it. Parallel with this assumption, in the present study, the individuals who reported the highest marital adjustment are self-oriented perfectionists who seek social support; whereas self-oriented perfectionists who did not seek social support have similar the mean score of marital adjustment.

The present study also showed that individuals who had low scores of SOP, who seek social support less often showed higher marital adjustment than who seek social support more often. Findings are consistent considering the collectivistic nature of the Turkish society mentioned above. On the other hand, the findings show that self-oriented perfectionists who have more persistent tendencies to cope with the stressful situations despite of the collectivist nature of the society when they seek social support tend to attribute their marital adjustment higher.

\section{Conclusion}

The results of the present study suggest that having SOP and tendency to attempt PC strategies are related to higher marital adjustment. SPP on men and SOP on women appeared to be two important perfectionism dimensions determining marital adjustment. Among individuals who tended to seek social support, having SOP had altered the scores of marital adjustment positively. Individuals without SOP reported lower marital adjustment when they tend to seek social support, which was assumed to be related to collectivistic nature of the Turkish society.

The current findings may be incorporated into clinical applications. On the other hand, the study has some limitations as well. First, generalization of the findings is limited to married individuals with certain characteristics (for example, they are from larger cities of Turkey and have relatively higher education level). Future studies may investigate the link among marital adjustment, perfectionism, and coping strategies with more specific samples (for example, newlyweds, remarried couples, etc.). More importantly, in the study, it is only assessed the perfectionism and coping strategy of one member of a couple, as well as only his/her appraisals of the relationship. Future studies would do well to investigate both members of an intimate partnership over time in order to understand how one (or both) partners' dyadic perfectionism and coping strategy affects marital adjustment. In 
Biyikoglu, E.B. \& Egeci , I.S. (2017). Marital Adjustment: The Role of Perfectionism, the Ways of Coping With Stress and Gender. New Trends and Issues Proceedings on Humanities and Social Sciences. [Online]. 07, pp 125-138. Available from: www.prosoc.eu

addition, since the type of the stressor changes the coping strategy, it is recommended to include the recent stressor types into future studies.

\section{References}

Billings, A. G. \& Moss, R. H. (1984). Coping, stress, and social resources among adults with unipolar depression. Journal of Personality and Social Psychology, 46, 877-891.

Blatt, S. (1995). The destructiveness of perfectionism: Implications for the treatment of depression. American Psychologist, 50, 1003-1020.

Bodenmann, G. \& Shantinath, S. D. (2004). The Couples Coping Enhancement Training (CCET): A new approach to prevention of marital distress based upon stress and coping. Family Relations, 53, 477-484.

Bouchard, G., Sabourin, S., Lussier, Y., Wright, J. \& Richer, C. (1998). Predictive validity of coping strategies on marital satisfaction: Cross-sectional and longitudinal evidence. Journal of Family Psychology, 12(1), 112-132.

Corcoran K. \& Fischer J. (1987). Measures for clinical practice. New York: Free Press.

Coyne, J. C. \& Downey, G. (1991). Social factors and psychopathology: Stress, social support, and coping processes. Annual Review of Psychology, 42, 401-425.

Derogatis, L. R. (1992). The Brief Symptom Inventory-BSI administration, scoring and procedures manual-II. Towson: Clinical Psychometric Research Inc.

Dimitrovsky, L., Levy-Shiff, R. \& Schattner-Zanany, I. (2002). Dimensions of depression and perfectionism in pregnant and nonpregnant women: their levels and interrelationships and their relationships to marital satisfaction. The Journal of Psychology, 136 (6), 631-646.

Dunkley, D. M. \& Blankstein, K. R. (2000). Self-critical perfectionism, coping, hassles, and current distress: A structural equation modelling approach. Cognitive Therapy and Research, 24, 713-730.

Endler, N. \& Parker, J. D. A. (1990). Multidimensional assessment of coping: A critical evaluation. Journal of Personality and Social Psychology, 58, 844-854.

Felsten, G. (1998). Gender and coping: Use of distinct strategies and associations with stress and depression. Anxiety, Stress, and Coping, 11, 289-309.

Fisiloglu, H. \& Demir, A. (2000). Applicability of the Dyadic Adjustment Scale for measurement of marital quality of Turkish couples. European Journal of Psychological Assessment, 16(3), 214-218.

Folkman, S. (1984). Personal control and stress and coping processes: A theoretical analysis. Journal of Personality and Social Psychology, 46, 839-852.

Folkman, S. \& Lazarus, R. S. (1980). An analysis of coping in a middle-aged community sample. Journal of Health and Social Behavior, 21, 219-239.

Flett, G. L., Hewitt, P. L. \& De Rosa, T. (1996). Dimensions of perfectionism, psychosocial adjustment, and social skills. Personality and Individual Differences, 20, 143-150.

Flett, G. L., Hewitt, P. L., Shapiro, B. \& Rayman, J. (2001-02). Perfectionism, beliefs, and adjustment in dating relationships. Current Psychology: Developmental, Learning, Personality, Social, 20(4), 289-311.

Flett, G. L., Russo, F. A. \& Hewitt, P. L. (1994). Dimensions of perfectionism and constructive thinking as a coping response. Journal of Rational-Emotive \& Cognitive-Behavior Therapy, 12(3), 163-179.

Flett, G. L., Sawatzky, D. L. \& Hewitt, P. L. (1995). Dimensions of perfectionism and goal commitment: A further comparison of two perfectionism measures. Journal of Psychopathology and Behavioral Assessment, 17, 111124. 
Biyikoglu, E.B. \& Egeci , I.S. (2017). Marital Adjustment: The Role of Perfectionism, the Ways of Coping With Stress and Gender. New Trends and Issues Proceedings on Humanities and Social Sciences. [Online]. 07, pp 125-138. Available from: www.prosoc.eu

Gencoz, F., Gencoz, T. \& Bozo, Ö. (2006). Hierarchical dimensions of coping styles: A study conducted with Turkish university students. Social Behavior and Personality, 34 (5), 525-534.

Habke, A. M. \& Flynn, C.A. (2002). Interpersonal aspects of trait perfectionism. In Flett, G. L. \& Hewitt, P. L. (Eds). Perfectionism: Theory, research, treatment (pp. 151-180). Washington DC: American Psychological Association.

Habke, A. M., Hewitt, P. L., Fehr, B., Callander, L. \& Flett, G. L. (1997). Perfectionism and behaviour in marital interaction. Poster presented at the annual meeting of the Canadian Psychological Association, Toronto, Ontario, Canada.

Habke, A.M., Hewitt, P.L. \& Flett, G.L. (1999). Perfectionism and Sexual Satisfaction in Intimate Relationships. Journal of Psychopathology and Behavioral Assessment, 21, 4, 307-322.

Haring, M., Hewitt, P. L. \& Flett, G. L. (2003). Perfectionism, coping, and quality of intimate relationships. Journal of Marriage and the Family, 65, 143-159.

Hewitt, P. L. \& Flett, G. L. (1991). Dimensions of perfectionism in unipolar depression. Journal of Abnormal Psychology, 100, 98-101.

Hewitt, P. L. \& Flett, G. L. (1991). Perfectionism in the self and social contexts: Conceptualization, assessment and association with psychopathology. Journal of Personality and Social Psychology, 60, 456-470.

Hewitt, P. L. \& Flett, G. L. (2002). Perfectionism and stress enhancement, perpetuation, anticipation, and generation in psychopathology. G. L. Flett \& P. L. Hewitt (Eds.), Perfectionism: Theory, research, and treatment (pp. 742-775). Washington, DC: American Psychological Association.

Hewitt, P. L., Flett, G. L. \& Blankstein, K. R. (1991). Perfectionism and neuroticism in psychiatric patients and college students. Personality and Individual Differences, 12, 273-279.

Hewitt, P. L., Flett, G. L. \& Endler, N. S. (1995). Perfectionism,coping and depression symptomology in a clinical sample. Clinical Psychology and Psychotherapy, 2, 47-58.

Hewitt, P. L., Flett, G. L. \& Mikail, S. F. (1995). Perfectionism and relationship adjustment in pain patients and their spouses. Journal of Family Psychology, 9(3), 335-347.

Hewitt, P. L., Flett, G. L., Turnbull-Donovan, W. \& Mikail, S. F. (1991). The Multidimensional Perfectionism Scale: Reliability, validity, and psychometric properties in psychiatric samples. Psychological Assessment: A Journal of Consulting and Clinical Psychology, 3(3), 464-468.

Hill, R. W., Zrull, M. C. \& Turlington, S. (1997). Perfectionism and interpersonal problems. Journal of Personality Assessment, 69, 81-103.

Hino, T., Takeuchi, T. \& Yamanouchi, N. (2002). A one year follow-up study of coping in patients with panic disorder. Comprehensive Psychiatry, 43(4), 279-284.

Kagıtcıbası, C. (1982). Sex roles, family and community in Turkey. In C. Kagıtcıbası \& D. Sunar (Eds.), Sex roles, value of children and fertility (pp. 151-180). Bloomington: Indiana University, Turkish Studies.

Karademas, E. C. \& Kalantzi-Azizi, A. (2004). The stress process, self-efficacy expectations, and psychological health. Personality and Individual Differences, 37, 1033-1043.

Lazarus, R. S. (2006). Emotions and interpersonal relationships: Toward a person-centered conceptualization of emotions and coping. Journal of Personality, 74, 9-46.

Lazarus, R. S. \& Folkman, S. (1984). Stress, appraisal and coping. New York: Springer.

Marin, T. J., Holtzman, S., DeLongis, A. \& Robinson, L. (2007). Coping and the response of others. Journal of Social and Personal Relationships, 24(6), 951-969. 
Biyikoglu, E.B. \& Egeci , I.S. (2017). Marital Adjustment: The Role of Perfectionism, the Ways of Coping With Stress and Gender. New Trends and Issues Proceedings on Humanities and Social Sciences. [Online]. 07, pp 125-138. Available from: www.prosoc.eu

Matud, M. P. (2004). Gender differences in stress and coping styles. Personality and Individual Differences, 37, 1401-1415.

Newth, S. \& DeLongis, A. (2004). Individual differences, mood, and coping with chronic pain in rheumatoid arthritis: A daily process analysis. Psychology \& Health, 19, 283-305.

Oral. M. (1999). The relationship between dimensions of perfectionism, stressful life events and depressive symptoms in university students: A test of diathesis-stress model of depression. Unpublished Master's Thesis, Middle East Technical University, Ankara.

Overbeek, G., Vollebergh, W., de Graaf, R., Scholte, R., de Kemp, R. \& Engels, R. (2006). Longitudinal associations of marital quality and marital dissolution with the incidence of DSM-III-R disorders. Journal of Family Psychology, 20, 284-291.

Pinquart, M. \& Silbereisen, R. K. (2008). Coping with increased uncertainty in the field of work and family life. International Journal of Stress Management, 15, 209-221.

Ptacek, J. T. \& Dodge, K. L. (1995). Coping strategies and relationship satisfaction in couples. Personality and Social Psychology Bulletin, 21, 76-84.

Ptacek, J. T., Smith, R. E. \& Dodge, K. L. (1994). Gender differences in coping with stress: When stressors and appraisal do not differ. Personality and Social Psychology Bulletin, 20, 421-430.

Sahin, N. H., \& Durak, A. (1994). Kısa semptom envanteri: Turk gencleri icin uyarlanması. Turk Psikoloji Dergisi, 9, 44-56.

Shafran, R. \& Mansell, W. (2001). Perfectionism and psychopathology: A review of research and treatment. Clinical Psychology Review, 21(6), 879-906.

Siva, N. A. (1991). Infertilite'de stresle bas etme, ogrenilmiş gucluluk ve depresyonun incelenmesi. Yayınlanmamıs Doktora Tezi, Hacettepe Universitesi, Ankara.

Spanier, G. B. (1976). Measuring dyadic adjustment: A new scale for assessing the quality of marriage and similar dyads. Journal of Marriage and Family, 38, 15-28.

Spangenberg, J. J. \& Theron, J. C. (1999). Stress and coping strategies in spouses of depressed patients. The Journal of Psychology, 133(3), 253-262.

Stoeber, J. (2012). Dyadic perfectionism in romantic relationships: Predicting relationship satisfaction and longterm commitment. Personality and Individual Differences, 53, 300-305.

Stoneman, Z., Gavidia-Payne, S. \& Floyd, F. (2006). Marital adjustment in families of young children with disabilities: associations with daily hassles and problem-focused coping. American Journal on Mental Retardation, 111(1), 1-14.

Whisman, M. A. (2007). Marital distress and DSM-IV psychiatric disorders in a population-based national survey. Journal of Abnormal Psychology, 116, 638-643.

Whisman, M. A., Uebelacker, L. A. \& Weinstock, L. M. (2004). Psychopathology and marital satisfaction: The importance of evaluating both partners. Journal of Consulting and Clinical Psychology, 72(5), 830-838.

Zaider, T. I., Heimberg, R. G. \& Lida, M. (2010). Anxiety disorders and intimate relationships: A study of daily processes in couples. Journal of Abnormal Psychology, 119, 163-17. 